\title{
AES/STEM GRAIN BOUNDARY ANALYSIS OF STABILIZED ZIRCONIA CERAMICS
}

\author{
A. J. A. Winnubst, P. J. M. Kroot t and A. J. BurgGraAF \\ Twente University of Technology, Department of Chemical Engineering, Laboratory for Inorganic Materials \\ Science, P.O. Box 217, 7500 AE Enschede, The Netherlands
}

(Received 19 January 1983; accepted 15 February 1983)

\begin{abstract}
Semiquantitative Auger Electron Spectroscopy (AES) on pure monophasic $\left(\mathrm{ZrO}_{2}\right)_{0.83}\left(\mathrm{YO}_{1.5}\right)_{0.17}$ was used to determine the chemical composition of the grain boundaries. Grain boundary enrichment with $Y$ was observed with an enrichment factor of about 1.5. The difference in activation energy of the ionic conductivity of the grain houndary compared with the bulk can be explained by the $\mathrm{Y}$ segregation.

When $\mathrm{Bi}_{2} \mathrm{O}_{3}$ is introduced into this material and second phase appears along the grain boundaries of the cubic main phase. Energy dispersive X-ray analysis (EDS) on a scanning transmission electron microscope (STEM) shows an enrichment of bismuth at the grain boundaries of this second phase.
\end{abstract}

\section{INTRONICTION}

In most ceramic materials a difference in structure and properties between grain boundaries and bulk is found $[1,2]$. In most cases segregation of impurities to the grain boundaries occurs. The segregation layer has a difference in chemical composition if this is compared with the bulk but has the same crystal structure. This layer has a thickness of a few nanometers [3].

Grain boundary segregation in ceramic materials is qualitatively well known, but quantitatively there is hardly any knowledge of the amount of segregation.

It is also possible that a second phase occurs which in most cases is situated at grain boundary edges or multiple grain junctions of the main phase grains [4].

This study has been started because of the observed differences between bulk and grain boundary conductivity reported in literature and in our previous work. Tien [5] reported a higher total conductivity for calcia stabilized zirconia when he used specimens with smaller grains. He therefore suggested that grain boundaries may have a higher conductivity than the bulk. Van Dijk et al. [6] and Verkerk et al. [7, 8] however found a lower grain boundary conductivity compared with the bulk. At $773 \mathrm{~K}$ the specific grain boundary conductivity of pure monophasic $\left(\mathrm{ZrO}_{2}\right)_{0.83}\left(\mathrm{YO}_{1.5}\right)_{0.17}$ was found to be a hundred times lower than that of the bulk [8].

Impurities are sometimes introduced for lowering the sintering temperature or improving mechanical or electrical behaviour. $\mathrm{Bi}_{2} \mathrm{O}_{3}$ is introduced to yttria stabilized zirconia as a sinter aid. This results in a decrease in conductivity compared with the pure material $[8,9]$. A second phase was observed in this $\mathrm{Bi}$-doped material. In most cases a $\mathrm{Bi}_{2} \mathrm{O}_{3}$ rich phase is found around the main phase grains of various bismuth doped ceramic materials such as $\mathrm{ZnO} / \mathrm{Bi}_{2} \mathrm{O}_{3}$ varistors [10] and $\mathrm{SrTiO}_{3}$ boundary layer capacitor material $[3,11]$.

In order to obtain chemical information of the grain boundary, Auger electron spectroscopy (AES) was ap-

†Address: N. V. Philips, H. I. G. Elcoma, Eindhoven, The Netherlands. plied. This technique provides information about the chemical composition of the outer atomic layers. The analysis of the grain boundaries by means of AES necessitates fracturing of the ceramic along the grain boundaries (intergranular).

A method which does not require intergranularly broken interfaces is that of energy dispersive $X$-ray analysis on thin foils with a scanning transmission electron microscope (STEM). When thin foils are used the $\mathrm{X}$-ray beam spread is reduced. However STEM analysis of the segregation layer includes a large contribution from the adjacent matrix. Therefore a small enrichment of the grain boundary with one of the components cannot be detected [12].

In this study we have analysed the chemical composition of pure ultrafine grained $\left(\mathrm{ZrO}_{2}\right)_{0.83}\left(\mathrm{YO}_{1.5}\right)_{0.17}$ by means of AES. The results are interpreted in a (semi-) quantitative way by using a series of standards with known compositions. The applicability of the method for grain boundary analysis of the main components of oxides is discussed. $\mathrm{Bi}_{2} \mathrm{O}_{3}$ doped $\left(\mathrm{ZrO}_{2}\right)_{0.83}\left(\mathrm{YO}_{1.5}\right)_{0.17}$ is analysed by means of AES and STEM. The observed data give some information of the distribution and chemical composition of the different phases. Finally the experimentally determined chemical composition of the grain boundary is used to interpret the results of the electrical data previously published $[7,8]$.

\section{EXPERIMENTAL METHODS}

\subsection{Preparation of the samples}

As raw material for the synthesis of $\left(\mathrm{ZrO}_{2}\right)_{0.83}$ $\left(\mathrm{YO}_{1.5}\right)_{0.17}$ (ZY17) ceramic we used ultra fine grained powders prepared by the alkoxide method as previously reported [7], which yields a pure and sinter reactive powder. A relative density of more than $95 \%$ was achieved after isostatically pressing at $400 \mathrm{MPa}$ and sintering for 3 hours at $1456 \mathrm{~K}$. The resultant grain size amounted $0.4 \mu \mathrm{m}[7]$.

$\mathrm{Bi}_{2} \mathrm{O}_{3}$ was added to the $\mathrm{ZY} 17$ powder by means of dry milling. When $2.3 \mathrm{~mol} \%$ of $\mathrm{Bi}_{2} \mathrm{O}_{3}$ was added the ceramic material reached a relative density of more than $95 \%$ 
after sintering at $1275 \mathrm{~K}$ with an average grain size of $0.8 \mu \mathrm{m}$ [13]. Addition of $0.74 \mathrm{~mol}^{2} \mathrm{Bi}_{2} \mathrm{O}_{3}$ gave a dense material when sintered at $1375 \mathrm{~K}$ (grain size $0.7 \mu \mathrm{m}$ ) [8].

AES analysis of grain boundaries requires intergranularly fractured surfaces. $\mathrm{Bi}_{2} \mathrm{O}_{3}$ doped $\mathrm{ZY} 17$ fractures integranularly while pure and dense ZY 17 exhibits a transgranularly fractured surface [14]. We used a porous material to obtain integranular surfaces for the pure material. This specimen was pressed isostatically at $40 \mathrm{MPa}$. The same temperature treatment as mentioned above then yields a material with a relative density of $81 \%$ which fractures intergranularly for about $80 \%$. The resultant average grain size amounted $0.4 \mu \mathrm{m}$.

Specimens used for STEM were mechanically thinned to about $50 \mu \mathrm{m}$. The sample ( $3 \mathrm{~mm}$ in diameter) was then placed on an electron microscope grid with the central area of this grid removed. Further thinning was performed with an argon ion beam with a diameter of $1 \mathrm{~mm}$ at a glancing angle of $20^{\circ}$ at both sides of the sample. The ion current used was about $15 \mu \mathrm{A}$ per gun at $4.5 \mathrm{kV}$. A TEM picture of the specimen could be made after about 50 hours ion thinning. X-Ray energy dispersive analysis (E.D.S.) of these samples were performed on a scanning transmission electron microscope (STEM) type JEOL. $200 \mathrm{CT}$ with an EDS unit (type EDAX) mounted on it.

\subsection{Auger electron spectroscopy}

2.2.1 Method of analysis. The composition of the fractured surfaces was determined on rods which were fractured under uitra high vacuum. In this way surface contamination could be avoided. The Auger analyses were performed with a cylindrical mirror analyser, type 10-155 (Physical Electronics). This analyser has a coaxial electron gun with a beam diameter of about $100 \mu \mathrm{m}$. The analyses were performed using a primary beam energy of $3 \mathrm{keV}$ and an electron beam current of $0.25 \mu \mathrm{A}$. No sample charging occurred under these conditions when clean specimens were used. In some cases indepth information of the fractured surface was obtained by sputter etching. The argon ion beam used for sputtering had an energy of $2 \mathrm{KeV}$ and a beam current of about $30 \mu \mathrm{A} / \mathrm{cm}^{2}$.

The handbook of Auger spectroscopy [15] gives standard spectra for only a few oxides and concentrates mainly on pure elements. The energy and shape of the Auger lines of most elements are known to differ in chemical compounds with respect to the pure elements [16]. Because of this difference, standard oxide spectra were made of $\mathrm{Y}, \mathrm{Zr}$ and $\mathrm{Bi}$. $\mathrm{Y}$ and $\mathrm{Zr}$ standard oxide spectra were obtained from pressed $\mathrm{ZrO}_{2}$ and $\mathrm{Y}_{2} \mathrm{O}_{3}$ powders while a standard oxide spectrum of $\mathrm{Bi}$ was obtained from molten $\mathrm{BiO}_{3}$. The standard oxide spectra are shown in Fig. 1.

Auger spectra of bulk and grain boundaries taken from freshly fractured ZY17 specimens are shown in Figs. 2(a) and 2(b) respectively. In these spectra there is a partial overlap of the Auger spectra of $\mathrm{ZrO}_{2}$ and $\mathrm{Y}_{2} \mathrm{O}_{3}$ as is shown by comparison of Fig. 2 with Fig. 1. For semiquantitative analysis of $Y$ in the spectra of Fig. 2 the positive part of the Auger line at $77 \mathrm{eV}$ was used. This line is the only available $\mathrm{Y}$ line in $\mathrm{Zr}-\mathrm{Y}$ compounds

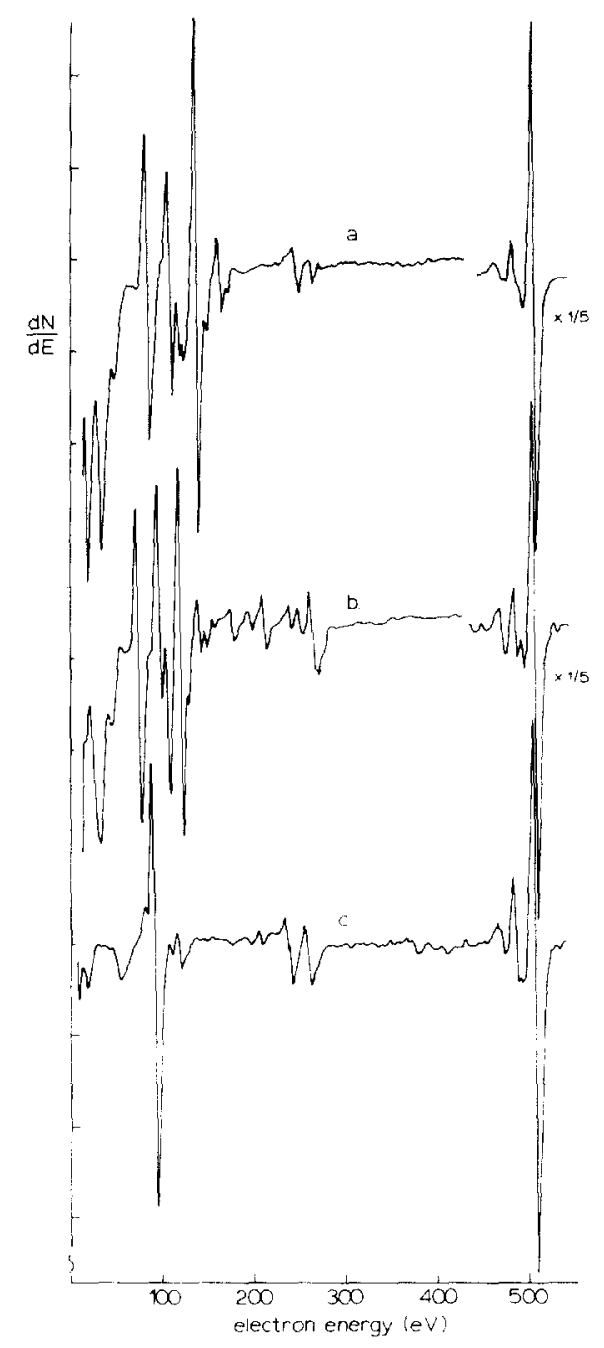

Fig. 1. Auger spectra of $\mathrm{ZrO}_{2}(\mathrm{a}), \mathrm{Y}_{2} \mathrm{O}_{3}(\mathrm{~b})$ and $\mathrm{Bi}_{2} \mathrm{O}_{3}$ (c).

which is free from overlap. The peak intensity was measured with respect to the base line. The $140 \mathrm{eV} \mathrm{Zr}$ line in the spectra of Fig. 2 is not disturbed and is used for $\mathrm{Zr}$ analysis. Bismuth was determined in the Auger spectra of $\mathrm{Zr}-\mathrm{Y}-\mathrm{Bi}$ compounds by means of the negative part of the $95 \mathrm{eV}$ Auger line which shows no overlap with any $\mathrm{Y}$ or $\mathrm{Zr}$ line.

A semiquantitative determination of the compositions was now obtained by comparing the Auger spectra with standard spectra taken from samples with a similar and known composition. In this way all relevant parameters are the same for standards and samples. The standard was obtained from a transgranular fractured surface of ZY17 (Fig. 2a). This coarse grained ceramic material had a relative density of more than $95 \%$ and an average grain size of $35 \mu \mathrm{m}$.

No change in $\mathrm{Y}$ to $\mathrm{Zr}$ intensity ratio was found after removing an increasing amount of atomic layers by means of $\mathrm{Ar}^{+}$ion bombardment. We can use this material as a standard because no preferential sputtering of $\mathrm{Y}$ or $\mathrm{Zr}$ was expected [17] nor observed.

The relative sensitivity of the $\mathrm{Y}$ and $\mathrm{Zr}$ signals in the oxide form was determined from the ZY17 standard 


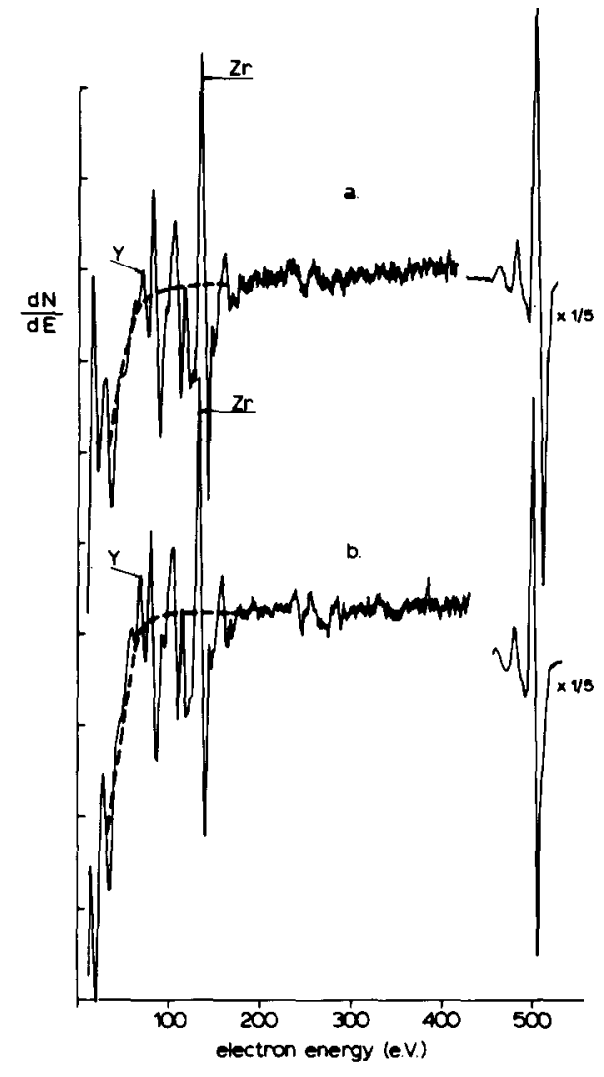

Fig. 2. Auger spectra of ZY17 specimens: (a) coarse grained transgranularly fractured ZY17; (b) Grain boundary surface of fine grained ZY17.

spectrum using Palmberg's equation [15]:

$$
C_{x}=\frac{I_{x} / S_{x}}{\sum_{\alpha}\left(I_{\alpha} / S_{\alpha}\right)}
$$

where $C_{x}$ is the concentration (in at \%) of element $x . I_{x}$ and $S_{x}$ are respectively the peak intensity and the relative elemental sensitivity factor of the Auger line of element $x$ used for quantification. In our work the sensitivity of the elements in question is calculated relative to that of oxygen. The relative elemental sensitivity factor of $O$ was taken from Palmberg[15]. $\dagger$ It is assumed that this factor of oxygen in different oxides does not change with the composition. The summation is over the peak of each element $(\alpha)$ which is considered for quantification.

The sensitivity factor of $\mathrm{Bi}$ was obtained from the $\mathrm{Bi}_{2} \mathrm{O}_{3}$ standard spectrum. In Table 1 the calculated sensitivity factors of $\mathrm{Zr}, \mathrm{Y}$ and $\mathrm{Bi}$ in the oxide form are compared with those of the pure elements according to Palmberg [15].

It can be seen from this table that Palmberg's data cannot be simply used for quantitative interpretation of Auger spectra from oxides.

†Elemental sensitivity factors are taken by Palmberg [15] relative to pure silver.
Table 1. Auger sensitivity factors of pure elements and the oxide form $\left(E_{p}=3 \mathrm{kV}\right)$

\begin{tabular}{|l|c|c|}
\hline olement & $\begin{array}{c}\text { pure element } \\
\text { (Paimberg [15]) }\end{array}$ & oxide form \\
\hline $\mathbf{z x}$ & 0.2 & 0.25 \\
$\mathrm{Y}^{*}$ & 0.17 & 0.33 \\
$\mathrm{B1}$ & - & 0.6 \\
0 & 0.5 & 0.5 \\
\hline
\end{tabular}

*The intensity of the main $Y$-Auger line at $122 \mathrm{eV}$ was calculated for oomparioon with ralmberg's relative elemental sensitivity factor of this line.

By means of equation 1 and the sensitivity factors given in Table 1 the chemical composition of some fractured surfaces can now be semiquantitatively determined.

2.2.2 Discussion of the method. It is not expected that the energy and shape of the Auger lines in a solid solution differs from those obtained from the standard spectra given in Fig. 1. This point could not be confirmed directly with spectra obtained from fractured surfaces of solid solutions because the Auger spectra of $\mathrm{ZrO}_{2}, \mathrm{Y}_{2} \mathrm{O}_{3}$ and $\mathrm{Bi}_{2} \mathrm{O}_{3}$ partly overlap. However, as far as $\mathrm{Zr}$ lines are concerned no deviation from the pure $\mathrm{ZrO}_{2}$ standard spectrum could be detected in a spectrum taken from a $\mathrm{CaO}$ stabilized $\mathrm{ZrO}_{2}$ sample where all the $\mathrm{Zr}$ lines are free.

It seems to be necessary to use a dense material as standard for $\mathrm{Zr}-\mathrm{Y}$ compounds. A decrease in the $\mathrm{Y}$ to $\mathrm{Zr}$ intensity ratio as function of $\mathrm{Ar}^{+}$ion sputtering time was observed when coarse grained $(\approx 40 \mu \mathrm{m}) \mathrm{ZY} 17$ or $\mathrm{ZY} 26$ with a relative density of about $90 \%$ or less was used. If this type of artefact has to be avoided the material used as a standard must have a relative density of at least $95 \%$ and of course a transgranular fractured surface. The reason for this behaviour is at present not understood.

For quantitative interpretation of the Auger spectra it is necessary to note that the shape of the broad secondary electron peaks with an energy smaller than $50 \mathrm{eV}$ differs between the various samples. This results in a difference in the base line form between the differentiated Auger spectra due to differences in background intensities. The choice of the base line is rather inaccurate but shows the same path in standard and specimen spectra. The observed intensity differences with respect to this base line are therefore real (see Section 3.1).

A problem of the interpretation of the Auger data of $\mathrm{Bi}_{2} \mathrm{O}_{3}$ solid solutions is the migration of $\mathrm{Bi}$ away from the analysed surface under influence of the electron beam. In Fig. 3 the decrease of the Bi-signal is given as function of the electron bombardment time using beams with very low electron density as employed in this work. The relevant Auger signals were measured directly after the electron beam was switched on in order to avoid this effect as much as possible.

Because $\mathrm{SiO}_{2}$ has an Auger line at $76 \mathrm{eV}$, the presence of Si may have a strong influence on the Auger data of our materials. No traces of Si could be detected however using the $1619 \mathrm{eV}$ Si Auger line as Si indicator. Despite the fact that this Auger line has a rather weak elemental sensitivity 


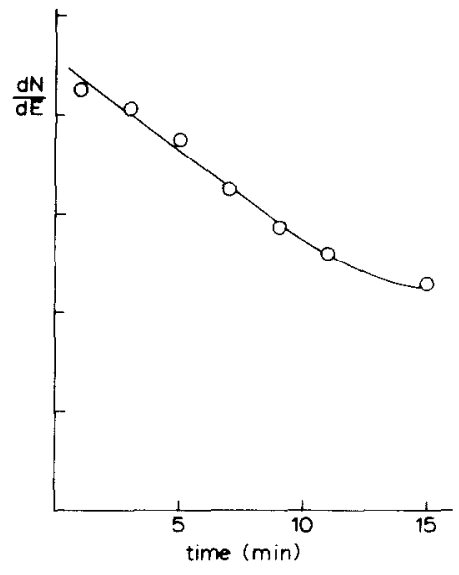

Fig. 3. Bi signal intensity as function of the electron bombardment time $(3 \mathrm{keV}, 0.05 \mu \mathrm{A})$.

we can conclude that significant concentrations of Si are absent.

2.2.3 Sputter etching. Indepth information obtained after ion sputter etching must be carefully interpreted. The quantitative use of Auger data achieved from sputter profiles is rather doubtful. One of the problems is that the cylindrical mirror analyser and the ion gun "see" the surface from different angles with the result that the sputtered surface is not completely the same as the analysed surface. This effect is important on roughly broken and/or porous surfaces.

Preferential sputtering can affect the results considerably. In the $\mathrm{Bi}_{2} \mathrm{O}_{3}-\mathrm{Er}_{2} \mathrm{O}_{3}$ system we found the sputter velocity of $\mathrm{Bi}_{2} \mathrm{O}_{3}$ to be much higher than for $\mathrm{Er}_{2} \mathrm{O}_{3}$. This preferential sputtering of $\mathrm{Bi}$ probably also occurs in $\mathrm{Bi}_{2} \mathrm{O}_{3}-\mathrm{ZrO}_{2}-\mathrm{Y}_{2} \mathrm{O}_{3}$ systems.

Finally after prolonged sputtering ( $>1 \mathrm{~min}$ ) reduction of $\mathrm{ZrO}_{2}$ occurs even at the low beam current we used. This causes the $147 \mathrm{eV}$ line of the pure element to emerge. Both the $140 \mathrm{eV}$ line of the oxide and the $147 \mathrm{eV}$ line must now be considered.

\section{RESULTS AND DISCUSSION}

3.1 Grain boundary composition of pure ZY17

The Auger spectra of trans- and intergranularly fractured ZY17 are shown in Figs. 2(a) and 2(b) respectively. Here it is seen that qualitatively the $\mathrm{Y} / \mathrm{Zr}$ peak intensity ratio of grain boundary spectrum (Fig. 2b) is higher than that of the bulk (Fig. 2a).

The inaccuracy in the choice of the basc line is smaller than the observed differences in the peak intensity ratio between the two spectra. Therefore it can be concluded that yttrium enrichment occurs at the grain boundaries of ultrafine grained ZY17. Using the sensitivity factors given in Table 1 a grain boundary composition of 24.5 $\mathrm{mol} \% \mathrm{YO}_{1.5}$ and $75.5 \mathrm{~mol} \% \mathrm{ZrO}_{2}$ is calculated.

The $\mathrm{Y}$ enrichment at the grain boundary is also indicated by a decrease of the $Y$ signal as function of the $\mathrm{Ar}^{+}$ion sputtering time. After 30 seconds of ion sputtering the $\mathrm{Y} / \mathrm{Zr}$ peak intensity ratio becomes constant. No quantitative information can be obtained from the observed sputter profile with respect to the real concentration profile because of surface roughness effects (see
Section 2.2). For the same reason the thickness of the $\mathrm{Y}$-segregation layer cannot be determined with any precision but is estimated to be of the order of 2-4 $\mathrm{nm}$. So in a monophasic ZY17 solid solution segregation of one of the main components to the grain boundary is observed. The measured differences in chemical composition between bulk and grain boundary can partly explain the earlier observed differences in electrical data of bulk and grain boundary $[7,8]$.

The grain boundary composition was found to be ZY24.5. Because of the small grain boundary thickness indicated in the above-mentioned discussion and by electrical measurements (about $4 \mathrm{~nm}[8]$ ) and the small enrichment factor $(\approx 1.5)$ we may conclude that the bulk composition is still ZY17. This higher amount of $Y$ in the grain boundary explains the decreased grain boundary conductivity. This will be discussed below.

In general the conductivity as a function of temperature can be described by means of the Arrhenius equation: $\sigma=\sigma_{0} \exp \left(-E_{a} / R T\right)$, where $\alpha_{0}$ is the preexponential factor, $E_{a}$ the activation energy for ionic motion, $R$ the gas constant and $T$ the temperature. At $T>800 \mathrm{~K}$ Verkerk et al. [8] found values for $E_{a}$ of 79 and $110 \mathrm{~kJ} \mathrm{~mol}^{-1}$ for respectively bulk and grain boundary conductivity of ZY17 prepared in the same way as mentioned in Section 2.1. Ioffe et al. $[18\rceil$ reported for ZY17 and ZY24.5 $E_{a}$ values of 85 and $108 \mathrm{~kJ} \mathrm{~mol}^{\prime}$ respectively in the temperature range of $1100-1300 \mathrm{~K}$. The differences we have found between $E_{c x}$ of bulk and grain boundary can therefore be explained very well in terms of $Y$ segregation to the grain boundary. According to Inozemtsev et al. [19] and Suzuki et al. [20] the conductivity of ZY24.5 is about 10 times lower than that of ZY17. The experimentally observed specific grain boundary conductivity is, however, a hundred times lower $[7,8]$. Preliminary calculations suggest that this might be explained by space charge effects. This point is now further investigated.

\subsection{Grain boundary composition and microstructure of} $\mathrm{Bi}_{2} \mathrm{O}_{3}$ doped $\mathrm{ZY} 17$

AES measurements. The Auger spectra obtained from intergranularly fractured surfaces of the $\mathrm{Bi}_{2} \mathrm{O}_{3}$ doped samples showed a strong $\mathrm{Bi}$-signal. Especially in the sample doped with 2.3 mol\% $\mathrm{Bi}_{2} \mathrm{O}_{3}$ almost no $\mathrm{Y}$ could be detected on the freshly fractured surface. The chemical composition is determined using the sensitivity factors as given in Table 1. These results are given in Table 2 and compared with the total composition of samples measured by X-ray fluorescence. It can be seen from this

Table 2. Chemical composition of intergranular fractured surfaces and overall composition $\mathrm{Bi}_{2} \mathrm{O}_{3}$ doped $\mathrm{ZY} 17$

\begin{tabular}{|c|c|c|c|c|}
\hline \multirow[b]{2}{*}{ Element } & \multicolumn{2}{|c|}{$2 \mathrm{Y}_{17}+0.74 \mathrm{~mol} * \mathrm{Hi}_{2} \mathrm{O}_{3}$} & \multicolumn{2}{|c|}{$2 \times 17+2.3 \mathrm{~mol}+\mathrm{at} \mathrm{O}_{3}$} \\
\hline & $\begin{array}{l}\text { Intergranular } \\
\text { surface com- } \\
\text { position (AES) }\end{array}$ & $\begin{array}{l}\text { overall } \\
\text { composition } \\
{\left[\begin{array}{l}{[4]}\end{array}\right.}\end{array}$ & $\begin{array}{l}\text { Intexgranular } \\
\text { surface com- } \\
\text { position (AES) }\end{array}$ & $\begin{array}{l}\text { Overall } \\
\text { composition } \\
\text { [13! }\end{array}$ \\
\hline $\operatorname{zr}($ ats $)$ & 7 & 20,0 & $t:$ & $\because 6$. \\
\hline$y(a t)$ & 3 & 5 & 1 & 3.6 \\
\hline$B i$ (at: $)$ & 15 & 0.6 & $\therefore 6$ & 1.0 \\
\hline$O(a t s)$ & 75 & 65.6 & 60 & tים \\
\hline
\end{tabular}




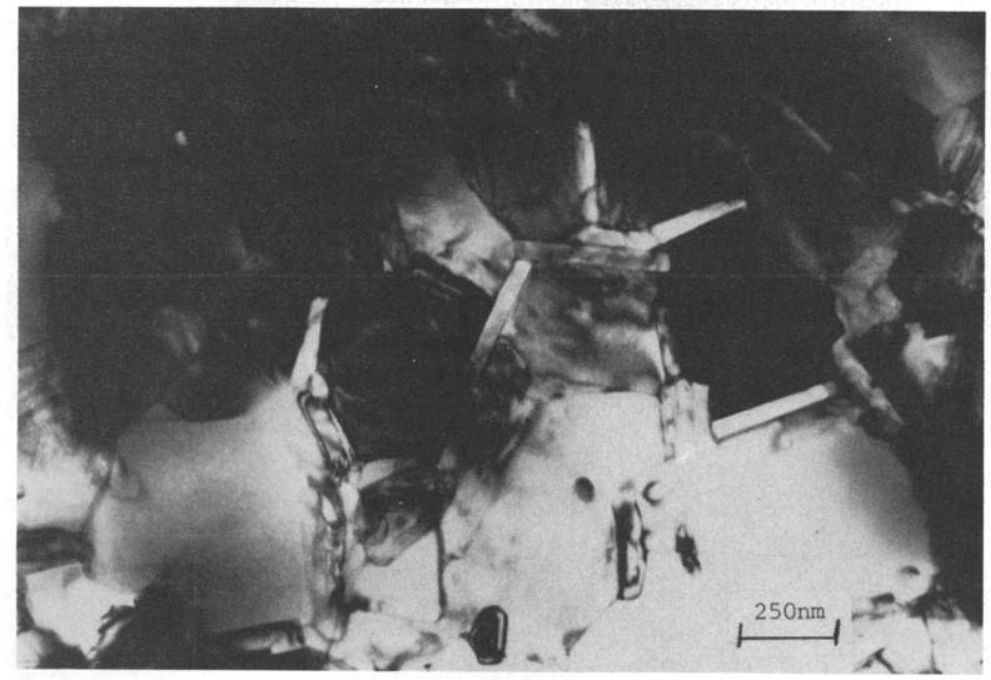

Fig. 4. TEM picture of $\mathrm{ZY} 17$ doped with $2.3 \mathrm{~mol} \% \mathrm{Bi}_{2} \mathrm{O}_{3}$.

table that an enrichment of bismuth occurs on the intergranularly fractured surfaces of these samples. This $\mathrm{Bi}$ rich layer is rapidly removed after $\mathrm{Ar}^{+}$sputtering during $15 \mathrm{sec}$. while an $\mathrm{Y}$ rich surface is developing.

(S)TEM/EDS measurements. In Fig. 4 a T.E.M. picture of an ion thinned ZY17 specimen doped with $2.3 \mathrm{~mol} \% \mathrm{Bi}_{2} \mathrm{O}_{3}$ is shown.

This material clearly shows two different types of grains. One type, the so-called main phase grains, have a size of $0.8 \mu \mathrm{m}$. The second phase grains have a width of $50 \mathrm{~nm}$. EDS analysis was performed on this specimen. The intensity ratio of the $K_{\alpha}$ lines of $\mathrm{Zr}$ and $\mathrm{Y}$ were taken to determine the chemical composition with respect to these elements. In this way a composition of ZY21 was calculated for the main phase grains. Earlier X-ray diffraction measurements [13] show that the large main phase grains can be ascribed to a cubic ZY22 phase which agrees very well with the above mentioned EDS results.

In the small second phase grains of Fig. 4 no measurable quantities of yttrium were detected by means of EDS. X-ray diffraction on this specimen indicated an amount of $21 \mathrm{~mol} \%$ monoclinic $\mathrm{ZrO}_{2}$ [13]. The elongated smaller grains in Fig. 4 can therefore be ascribed to monoclinic $\mathrm{ZrO}_{2}$. This distribution of the monoclinic phase is rather unfavourable for the ionic conductivity of the material.

The X-ray $L$-line was used for bismuth analysis by means of EDS. In this specimen (Fig. 4) some bismuth is detected in the bulk of both types of grains at the grain boundaries of the main phase grains. Bismuth enrichment with a factor of about 10 is observed at the grain boundaries of the second phase grains. This area with relatively high $\mathrm{Bi}$ content probably forms a diffusion path with high diffusion velocity during sintering. This might explain the very strong effect of $\mathrm{Bi}_{2} \mathrm{O}_{3}$ on the sintering temperature reported earlier [8].

From the Auger measurements and STEM/EDS analysis we can also understand why the $\mathrm{Bi}_{2} \mathrm{O}_{3}$ doped ZY17 samples mainly fracture along the Bi-rich zone.
The distribution and shape of the monoclinic second phase indicate that the location of this second phase is the weakest region of $\mathrm{Bi}_{2} \mathrm{O}_{3}$ doped yttria stabilized zirconia [14].

\section{CONCLUSIONS}

For semi-quantitative interpretation of the Auger spectra of oxide materials one cannol simply use the relative elemental sensitivity factors of the pure elements according to Palmberg [15]. The use of oxide standard materials and of "oxide sensitivity factors" is necessary.

AES analysis of the grain boundaries of pure monophasic ZY17 shows an enrichment of yttrium. This segregation of yttrium to the grain boundary partly explains the lower conductivity of the grain boundary compared with the bulk.

AES of intergranular surfaces of $\mathrm{Bi}_{2} \mathrm{O}_{3}$ doped $\mathrm{ZY} 17$ shows a strong enrichment of $\mathrm{Bi}$ compared with the overall composition.

When $2.3 \mathrm{~mol} \%$ of $\mathrm{Bi}_{2} \mathrm{O}_{3}$ is added to $\mathrm{ZY} 17$ a monoclinci $\mathrm{ZrO}_{2}$ phase appears, which partly isolates the cubic grains from each other. There is a pile up of $\mathrm{Bi}_{2} \mathrm{O}_{3}$ along the grain boundaries of this second phase. The higher amount of $\mathrm{Y}$ in the cubic phase and the unfavourable distribution of the monoclic phase result in a decrease in conductivity compared with pure ZY17.

Acknowledgements-We would like to thank Mr. J. Snoeyenbos for his assistance with the ion thinning of the specimens and Dr. J. Beyer for his help with the STEM measurements. The financial assistance of the material group of Elcoma (Philips Electronic Industries Eindhoven) is greatly appreciated.

\section{REFERENCES}

1. Kingery W. D., J. Am. Ceram. Soc. 57, 1 (1974).

2. Kingery W. D., J. Am. Ceram. Soc. 57, 74 (1974).

3. Bongers P. F. and Franken P. E. C. Advances in Ceramics (Edited by L. M. Levinson), Vol. 1, p. 38. The American Ceramic Society, Columbus, Ohio (1981)

4. Beekmans N. M. and Heyne L., Electrochimica Acta 21, 303 (1976).

5. Tien T. Y., J. Appl. Phys. 35, 122 (1964). 
6. Van Dijk T. and Burggraaf A. J., Phys. Stat. Solidi (A) 63, 229 (1981).

7. Verkerk M. J., Middelhuis B. J. and Burggraaf A. J., Solid St. Ionics 6, 159 (1982).

8. Verkerk M. J., Winnubst A. J. A. and Burggraaf A. J., J. Mater. Sci. 17, 3113 (1982).

9. Keizer K., Burggraaf A. J. and De With G., J. Mater. Sci. 17, 1095 (1982).

10. Sainkar S. R., Badrinarayanan S., Sinha A. P. B. and Date S. K., Surface Interface Anal. 3, 142 (1981).

11. Franken P. E. C., Viegers M. P. A. and Gehring A. P., J. Am. Ceram. Soc. 64, 687 (1981).

12. Bender B., Williams D. B. and Notis M. R., J. Am. Ceram. Soc. 63, $542(1980)$.

13. Winnubst A. J. A., Verkerk M. J. and Burggraaf A. J., Advan. Ceram. 6 (1983) to be published.
14. Winnubst A. J. A., Keizer K. and Burggraaf A. J., J. Mater. Sci. 18, 1958 (1983).

15. Palmberg P. W., Riack G. E., Weber R. E. and McDonald N C., Handbook of Auger Spectroscopy, Physical Electronics. Edina, Minnesota (1972).

16. Allie G., Blanc E. and Dufayard D., Handbook of Surfaces and Interfaces (Edited by L. Dobrzynsky), Vol. 2 p. 321. Garland STPM Press, New York (1978).

17. Greene J. E., Klinger R. E., Barr T. L. and Welsch I.. B. Chem. Phys. Lett. 62, 46 (1979).

18. Ioffe A. I., Rutman D. S. and Karpachov S. V., Electrochim. Acta 23, 141 (1978).

19. Inozemtsev M. V. and Perfil ev M. V.. Electrochimiva 12. 1236 (1976).

20. Suzuki Y., Takahashi T. and Nagel N., Solid St. Ionics 3-4. 509 (1981). 